\title{
Alteration of Growth Responses in Established Cardiac Pressure Overload Hypertrophy in Rats with Aortic Banding
}

Heribert Schunkert, ${ }^{\star \star}$ Ellen O. Weinberg, ${ }^{*}$ Günter Bruckschlegel, ${ }^{\ddagger} \dot{A}$. J. Günter Riegger, ${ }^{\star}$ and Beverly H. Lorell*

*The Charles A. Dana Research Institute and Harvard-Thorndike Laboratory of Beth Israel Hospital, Department of Internal Medicine, Cardiovascular Division, Beth Israel Hospital, Harvard Medical School, Boston, Massachusetts 02215; and ${ }^{\ddagger}$ Klinik und Poliklinik für

Innere Medizin II, University of Regensburg, Franz-Josef Strauß Allee, 93042 Regensburg, FRG

\section{Abstract}

We examined the acute effects of elevated wall stress, norepinephrine, and angiotensin II on cardiac protein synthesis as well as protooncogene expression in hearts with established pressure overload left ventricular hypertrophy. Isolated rat hearts with chronic hypertrophy (LVH) were studied 12 wk after ascending aortic banding when systolic function was fully maintained. New protein synthesis (incorporation of $\left[{ }^{3} \mathrm{H}\right]$ phenylalanine [Phe]) was analyzed in isolated perfused rat hearts after a 3-h protocol; c-fos, c-jun, c-myc, and early growth response gene-1 (EGR-1) mRNA levels (Northern blot) were studied over a time course from 15 to $\mathbf{2 4 0}$ min of perfusion. Under baseline conditions (i.e., before mechanical or neurohormonal stimulation), $\left[{ }^{3} \mathbf{H}\right]-$ Phe-incorporation ( 280 nmoles/gram protein/h) and protooncogene mRNA levels were similar in age-matched control and LVH hearts. However, hearts with chronic LVH were characterized by a markedly blunted or absent $\left[{ }^{3} \mathrm{H}\right]-$ Phe-incorporation after acute imposition of isovolumic systolic load ( $90 \mathrm{mmHg} / \mathrm{gram}$ left ventricle), as well as norepinephrine $\left(10^{-6} \mathrm{M}\right)$, or angiotensin II infusion $\left(10^{-8} \mathrm{M}\right.$ plus prazosin $10^{-7} \mathrm{M}$ ) compared with nonhypertrophied control hearts. Similarly, stimulation of LVH hearts with acute systolic load or norepinephrine was associated with a significantly blunted increase of protooncogene mRNA levels relative to control hearts. The blunted induction of c-fos mRNA in LVH hearts was not due to feedback inhibition, since cycloheximide perfusion of hearts exposed to elevated wall stress further increased the differences between agematched control and LVH hearts.

The data suggest that acute molecular growth responses to mechanical or neurohormonal stimulation are altered in rat hearts with established LVH relative to nonhypertrophied control hearts. This alteration of molecular adaptations in hearts with compensatory hypertrophy may prevent inappropriate excess cardiac growth in response to mechanical and neurohormonal stimuli. (J. Clin. Invest. 1995.

This work was presented in part at the 66th Scientific Sessions of the American Heart Association, Atlanta, GA, 1993.

Address correspondence to Beverly H. Lorell, M.D., Cardiovascular Division, Beth Israel Hospital, 330 Brookline Avenue, Boston, MA 02215. Phone: 617-667-8727; FAX: 617-667-4833.

Received for publication 10 May 1995 and accepted in revised form 7 September 1995.

J. Clin. Invest.

(C) The American Society for Clinical Investigation, Inc.

0021-9738/95/12/2768/07 \$2.00

Volume 96, December 1995, 2768-2774
96:2768-2774.) Key words: hypertrophy • rat • protooncogene $\cdot$ angiotensin $\cdot$ norepinephrine

\section{Introduction}

In hypertension or valvular heart disease the myocardium is exposed to a long lasting pressure overload. Since cardiac myocytes are terminally differentiated cells without the ability to divide, cellular hypertrophy is the only mechanism to normalize the persisting elevation of systolic wall stress under these conditions. In normal myocardium, pathways involved in the induction of cardiac hypertrophy may be activated within a few minutes after the onset of pressure overload, suggesting that myocardial cells are continuously sensing changes in loading conditions (1-4). Early signals of the cellular growth response include induction of protooncogenes and stimulation of overall cardiac protein synthesis $(2,4)$. Pressure overload persisting for days or weeks induces multiple changes in the pattern of myocardial gene expression that finally result in a substantial remodeling of the heart's geometry and a fetal pattern of cellular biology $(5,6)$.

In later stages of chronic pressure overload or in the aging heart the capacity to respond to hypertrophic stimuli may diminish (7-10). The down-regulation of acute molecular responses to growth stimuli may prevent excess myocyte growth in hearts with chronic concentric hypertrophy. On the other hand, exhaustion of compensatory hypertrophy may contribute to cell loss, progressive fibrosis, impairment of diastolic and systolic function, as well as other sequelae of hypertensive heart disease (7, 11-13). However, little is known about signal transduction or molecular adaptations to mechanical or neurohormonal stress in established pressure overload hypertrophy. Thus, in the present investigation, we studied the immediate dynamic molecular responses to well-described mechanical and neurohormonal growth inducing stimuli on cardiac protooncogene induction and protein synthesis in isolated hearts from ascending aorticbanded adult rats with chronic left ventricular ( $\mathrm{LVH})^{1}$ and agematched normal controls.

\section{Methods}

Preparation of animals. Male Wistar rats (100 gram) were obtained from Charles River Breeding Laboratories (Wilmington, DE). Aortic stenosis was created in anesthetized weanling rats by placing a stainlesssteel clip of $0.6 \mathrm{~mm}$ internal diameter on the ascending aorta $(14,15)$. Sham-operation was performed in age-matched controls that underwent a left thoracotomy. Animals were fed a standard rat chow (Purina) and water ad libitum for 8,12 , and 20 wk until used for experimentation.

1. Abbreviations used in this paper: LVH, left ventricular hypertrophy; Phe, phenylalanine. 


\section{Perfusion of isolated hearts}

Rats were injected intraperitoneally with $25 \mathrm{mg}$ pentobarbital and the thorax was rapidly opened. Next, the hearts were quickly removed and placed in a water-jacketed constant temperature chamber. Retrograde perfusion of the coronary arteries was restored through a short cannula inserted in the aortic root, using a modified Krebs-Henseleit buffer as previously described in detail $(14,15)$. For measurement of protein synthesis, the buffer contained $0.5 \%$ albumin and a mixture of amino acids in the following concentrations: aspartic acid $38 \mu \mathrm{M}$, asparagine $64 \mu \mathrm{M}$, glutamic acid $207 \mu \mathrm{M}$, glutamine $656 \mu \mathrm{M}$, glycine $328 \mu \mathrm{M}$, alanine $559 \mu \mathrm{M}$, valine $226 \mu \mathrm{M}$, leucine $184 \mu \mathrm{M}$, isoleucine $99 \mu \mathrm{M}$, serine $285 \mu \mathrm{M}$, threonine $371 \mu \mathrm{M}$, methionine $57 \mu \mathrm{M}$, proline $246 \mu \mathrm{M}$, phenylalanine $400 \mu \mathrm{M}$, tyrosine $119 \mu \mathrm{M}$, tryptophane $84 \mu \mathrm{M}$, histidine $77 \mu \mathrm{M}$, lysine $532 \mu \mathrm{M}$, and arginine $157 \mu \mathrm{M}(16)$. The perfusate was equilibrated with a $5 \% \mathrm{CO}_{2}-95 \% \mathrm{O}_{2}$ gas mixture such that the perfusate $\mathrm{pH}$ was between 7.36 and 7.44 and the $\mathrm{pO}_{2}$ was approximately 550 $\mathrm{mmHg}$. Temperature of the hearts was kept constant at $35^{\circ} \mathrm{C}$ and monitored with a thermistor probe. Cardiac performance was allowed to stabilize for $10 \mathrm{~min}$ of buffer perfusion. Flow was then adjusted to achieve a coronary perfusion pressure of $80 \mathrm{mmHg}$ in control and 100 $\mathrm{mmHg}$ in LVH hearts and then kept constant throughout the experimental protocol such that a similar flow per gram left ventricular weight was achieved in control and LVH hearts $(10,14,15)$.

\section{Experimental protocols}

Time course of functional and morphological adaptations after aortic banding. Groups of 5 to 10 age-matched control hearts, as well as groups of five to ten hearts with LVH were studied after 8, 12, and 20 wk after banding of the ascending aorta. The time points were selected because we have previously established that this encompasses the period from compensated hypertrophy through the transition to failure (17-20). Left ventricular pressure was measured using a fluid-filled latex balloon, slightly larger than the left ventricular chamber, that was inserted into the left ventricle $(14,15)$ and connected to a Statham $\mathrm{P} 23 \mathrm{Db}$ pressure transducer (Statham Instruments Inc., Puerto Rico). Maximal LV systolic pressure was measured at a balloon volume that resulted in a left ventricular end-diastolic pressure of $10 \mathrm{mmHg}$.

Effects of wall stress on amino acid incorporation. Groups of six age-matched control hearts, as well as groups of six hearts with LVH, $12 \mathrm{wk}$ after banding, were subjected to an acute elevation of isovolumic systolic wall stress by distention of a fluid-filled balloon in the left ventricular chamber (10). The hearts were initially perfused for 10-15 min with flaccid left ventricles and no left ventricular pressure generation. LV balloon volume was adjusted to achieve a left ventricular developed pressure of $150 \mathrm{mmHg}$ in $\mathrm{LVH}$ and $100 \mathrm{mmHg}$ in control hearts resulting in a left ventricular developed pressure per gram of $\sim 90 \mathrm{mmHg} / \mathrm{g}$ in both groups. Using previous comparisons of LVH with control hearts, these adjustments allowed the abrupt generation of a peak left ventricular systolic wall stress that was similar in control and LVH groups, using an estimation of peak meridional left ventricular systolic wall stress which was calculated using the method of Isoyama et al (8).

After $60 \mathrm{~min}$, the generation of systolic pressure overload was stopped by deflation of the intracardiac balloon and hearts were perfused for another $120 \mathrm{~min}$ with the modified Krebs-Henseleit buffer in which $0.5 \mathrm{mCi} /$ liter $\left[{ }^{3} \mathrm{H}\right]$ phenylalanine was added. Thus, the hearts were allowed to incorporate tritiated phenylalanine into newly synthesized proteins for $2 \mathrm{~h}$. Morgan et al. have previously shown that phenylalanine incorporation in isolated hearts is linear for $2 \mathrm{~h}(21)$. Unlabeled phenylalanine, present in a defined concentration in the buffer, allowed the calculation of the incorporation of phenylalanine into cardiac proteins on a molar basis $(4,16,21)$.

Effects of angiotensin II and norepinephrine on amino acid incorporation. Separate groups of six isolated age-matched control hearts, as well as groups of six hearts with LVH were perfused with (1) norepinephrine $\left(1 \times 10^{-6} \mathrm{M}\right) ;(2)$ a mixture of angiotensin II $\left(1 \times 10^{-8} \mathrm{M}\right)$ and prazosin $\left(1 \times 10^{-7} \mathrm{M}\right)$ (Sigma Chemical Co., St. Louis, MO); or
(3) vehicle. Angiotensin II was combined with the $\alpha_{1}$-blocker prazosin to prevent any indirect stimulation of protein synthesis via activation of the postsynaptic sympathetic nervous system (22). Concentrations used in this experiment were derived from previous dose finding studies $(14,23-27)$. These experiments were carried out without a balloon in the left ventricle such that the left ventricle was flaccid to avoid stimulation by mechanical load (left ventricular systolic pressure $<20 \mathrm{mmHg}$ ). To assure that pressurization of the coronary vascular system was comparable in all groups, the gradual increase in coronary perfusion pressure of $20-30 \mathrm{mmHg}$ that was seen with angiotensin II and norepinephrine stimulation was matched in the vehicle-perfused hearts by slightly increasing coronary flow. Administration of the agonists was carried out for $60 \mathrm{~min}$ before $\left[{ }^{3} \mathrm{H}\right.$ ] phenylalanine was added for another $120 \mathrm{~min}$ of perfusion. To confirm that the isolated heart preparation was stable with aerobic metabolism for the 180 -min duration of the experiment, lactate extraction was confirmed in five hearts without balloon in the left ventricle for an 180-min perfusion period.

Effects of wall stress and norepinephrine on c-fos, c-jun, c-myc, and early growth response gene-1 expression. The time course of cardiac protooncogene induction in response to an abrupt elevation of systolic wall stress at a level of $90 \mathrm{mmHg} / \mathrm{gram}$ was first examined in groups of three isovolumic hearts that were stimulated for $15,30,60,120$, and $240 \mathrm{~min}$. The abrupt development of this level of systolic pressure was achieved by inflation of a balloon in the left ventricle to increase left ventricular preload with secondary increase in the level of systolic pressure generation (10). As previously reported, the magnitude of passive diastolic wall stretch employed does not cause protooncogene induction in the absence of systolic pressure generation (10). In additional experiments, the comparison of wall stress or norepinephrine-mediated protooncogene induction in LVH and control hearts was then carried out at the time point of maximal increase in mRNA levels. Groups of five control hearts, as well as groups of five hearts with LVH were stimulated with a left ventricular systolic developed pressure per gram LV of 90 $\mathrm{mmHg} / \mathrm{gram}$. Separate groups of five control hearts as well as five LVH hearts without a balloon in the left ventricle were perfused with norepinephrine $\left(1 \times 10^{-6} \mathrm{M}\right)$ for $60 \mathrm{~min}(\mathrm{c}-f o s, \mathrm{c}-j u n)$, or $120 \mathrm{~min}$ (c-myc, EGR-1). Thus, to avoid hemodynamic perturbations, left ventricular pressure was $<20 \mathrm{mmHg}$, and coronary perfusion pressure was adjusted to comparable levels between hearts perfused with norepinephrine or vehicle.

To study whether negative feedback regulation might explain reduced induction of protooncogenes in LVH hearts, four normal control hearts as well as four hearts with LVH were subjected to elevated wall stress in the presence of cycloheximide to allow superinduction of protooncogene mRNA levels (28).

\section{Biochemical analysis}

Protein synthesis. After the perfusion protocols, atria and great vessels were quickly removed. Left and right ventricles were blotted dry, balanced, and snap-frozen in liquid nitrogen. For measurement of protein synthesis, the methods of Morgan et al. (21) with modifications by Kent et al. (4) were used. An aliquot $(\sim 100 \mathrm{mg})$ was minced and homogenized in $1 \mathrm{ml}$ ice cold 5\% perchloric acid to denature proteins and to remove unincorporated $\left[{ }^{3} \mathrm{H}\right]$ phenylalanine. After centrifugation, the pellet was washed with $5 \%$ perchlorate, resuspended, and heated to $80^{\circ} \mathrm{C}$ to remove transfer RNA-bound $\left[{ }^{3} \mathrm{H}\right]$ phenylalanine. After centrifugation, the pellet was washed with $5 \%$ perchlorate and then resuspended in $0.2 \mathrm{~N} \mathrm{NaOH}$. A small aliquot $(50 \mu \mathrm{l})$ of this solution was used for protein assay and a second aliquot ( $500 \mu \mathrm{l})$ was used for liquid scintillation counting. Data were corrected for quench by extrapolation. The net protein synthesis by left or right ventricles during the $120 \mathrm{~min}$ of perfusion with $\left[{ }^{3} \mathrm{H}\right]$ phenylalanine was calculated as phenylalanine incorporation $(\mathrm{mol} / \mathrm{g}$ protein $/ \mathrm{h})=$ phenylalanine $(\mathrm{dpm} / \mathrm{g}$ protein $/ \mathrm{h}) /$ perfusate phenylalanine specific activity $(\mathrm{dpm} / \mathrm{mol})$, where dpm stands for decelerations per minute.

RNA measurements. Homogenization of left ventricles and RNA extraction was carried out using standard procedures $(10,14,29)$. Comparison of relative mRNA levels were made in reference to the same 
Table I. Weight and Function of Isolated Hypertrophied and Normal Hearts at 8, 12, and 20 wk after Ascending Aortic Banding

\begin{tabular}{|c|c|c|c|c|c|c|}
\hline & \multicolumn{2}{|c|}{8 wk } & \multicolumn{2}{|c|}{$12 \mathrm{wk}$} & \multicolumn{2}{|c|}{20 wk } \\
\hline & Control & LVH & Control & LVH & Control & LVH \\
\hline$n$ & 5 & 5 & 10 & 10 & 5 & 6 \\
\hline BW (grams) & $362 \pm 7$ & $347 \pm 13$ & $386 \pm 6$ & $333 \pm 9$ & $458 \pm 15$ & $490 \pm 12$ \\
\hline LV weight (grams) & $0.85 \pm 0.03$ & $1.10 \pm .10 *$ & $1.05 \pm .03$ & $1.51 \pm .04^{\ddagger}$ & $1.17 \pm .06$ & $1.93 \pm .08^{\ddagger}$ \\
\hline LV/B weight (grams/kg) & $2.35 \pm .18$ & $3.11 \pm .19^{\ddagger}$ & $2.75 \pm .09$ & $4.53 \pm .15^{\ddagger}$ & $2.56 \pm .15$ & $3.82 \pm .15^{\ddagger}$ \\
\hline LVP (mmHg) & $102 \pm 8$ & $147 \pm 12^{\ddagger}$ & $100 \pm 6$ & $162 \pm 10^{\ddagger}$ & $116 \pm 4$ & $160 \pm 10^{\ddagger}$ \\
\hline LV dev $\mathrm{P}$ (mmHg/gram) & $120 \pm 8$ & $143 \pm 17 *$ & $95 \pm 7$ & $107 \pm 6$ & $101 \pm 5$ & $85 \pm 4 *$ \\
\hline LVEDP (mmHg) & $10.3 \pm .3$ & $10.5 \pm .2$ & $9.5 \pm .2$ & $10.1 \pm .2$ & $10.1 \pm .2$ & $10.2 \pm .1$ \\
\hline Coronary flow (ml/min per gram) & $13.6 \pm .7$ & $13.2 \pm .8$ & $13.1 \pm .6$ & $13.3 \pm .8$ & $13.3 \pm .6$ & $12.8 \pm .9$ \\
\hline LV balloon vol (ml) & $.16 \pm .01$ & $.16 \pm .01$ & $.18 \pm .01$ & $.19 \pm .01$ & $.18 \pm .01$ & $.21 \pm .02 *$ \\
\hline
\end{tabular}

Measurements were made in isolated perfused hearts from age-matched control and hypertrophied hearts from rats 8,12 , and 20 wk after ascending aortic banding. Values are expressed in mean \pm SEM; BW (grams), body weight; LV weight (grams), left ventricular weight; LV/B weight (grams/ $\mathrm{kg}$ ), left ventricular weight in grams per kilogram body weight; LVP (mmHg), left ventricular systolic pressure; LV dev P (mmHg/grams), left ventricular developed pressure in $\mathrm{mmHg}$ per gram of left ventricle; LVEDP ( $\mathrm{mmHg}$ ), left ventricular end diastolic pressure; coronary flow in $\mathrm{ml}$ per min per gram of left ventricle; LV balloon vol. (ml), left ventricular constant balloon volume. $* P<0.05$ vs age-matched controls; ${ }^{\ddagger} P<0.01$ vs age-matched controls.

amount of total RNA applied per sample. Standard Northern blot analysis, using the formaldehyde-agarose method (30) was carried out to size-separate mRNAs. Next, samples were blotted onto nylon filters (Genescreen; New England Nuclear, Boston, MA). After prehybridization for $4 \mathrm{~h}$, the blots were hybridized overnight in a buffer to which alpha ${ }^{32} \mathrm{P}$-cDNA probes were added. After hybridization, blots were washed in $0.2 \times \mathrm{SSC}$ with $0.1 \%$ sodium dodecyl sulfate at room temperature for $10 \mathrm{~min}$, then three times at $60^{\circ} \mathrm{C}$ for $30 \mathrm{~min}$. Blots were exposed for $2 \mathrm{~d}$ to $\mathrm{x}$-ray film (Kodak XAR; Eastman Kodak Co., Rochester, NY). All studies of c-fos, c-jun, c-myc, and EGR-1 protooncogene mRNA expression were performed using murine cDNA probes (10). To control for possible sample variability, identical Northern blots were hybridized with a housekeeping cDNA probe (GAPDH) (10). Autoradiograms generated by Northern blots were scanned with a microdensitometer (Pharmacia LKD Inc., Piscataway, NJ) with background set to zero for each autoradiograph. The signal for protooncogene mRNA was divided by signal for the GAPDH mRNA for each sample and results were expressed as protooncogene/GAPDH mRNA ratios.

Statistical analysis All data are presented as mean \pm standard error. Phenylalanine incorporation or protooncogene/GAPDH mRNA ratios in LVH versus control were directly compared by Student unpaired $t$ tests. A two-way ANOVA and Fisher's exact test for post hoc analyses were used for multiple comparisons in case of three or more comparisons between groups. Significance was accepted for $p<0.05$.

\section{Results}

Functional and morphological characteristics after aortic banding. The model of ascending aortic banding in weanling rats allows a gradual adaptation of left ventricular function and development of concentric geometry since severity of aortic stenosis increases during growth of the animals $(17-20)$. Table I demonstrates the time course of functional and morphological adaptations in this model. Corroborating our previous observations in this model $(17-20)$, the present experiments show that left ventricular systolic function is preserved in LVH hearts studied 8 and $12 \mathrm{wk}$ after aortic banding; in contrast, by $20 \mathrm{wk}$ post banding contractile function assessed as left ventricular developed pressure per gram is depressed in comparison with age-matched controls at comparable preload. The present study on molecular adaptations to acute mechanical or neurohormonal stimulation was carried out after $12 \mathrm{wk}$ of aortic banding. At this time point, significant left ventricular hypertrophy was achieved but left ventricular systolic function was fully maintained (Table I).

Effects of wall stress on amino acid incorporation. Under baseline conditions, i.e. without stimulation by wall stress or neurohormones, the rate of phenylalanine incorporation into newly synthesized proteins was similar in isolated age-matched control rat hearts $(287 \pm 48 \mathrm{nmoles}$ phenylalanine/g protein/hr) and hearts with LVH after 12 wk of aortic banding ( $277 \pm 49$ nmoles phenylalanine/g protein/hr). In response to the abrupt elevation of left ventricular systolic wall stress for 60 minutes ( $\mathrm{LV}$ developed pressure of $90 \mathrm{mmHg} / \mathrm{gram} \mathrm{LV}$; LV systolic meridional wall stress of $287 \pm 30 \times 10^{3} \mathrm{dyn} / \mathrm{cm}^{2}$ in control and $301 \pm 30 \times 10^{3} \mathrm{dyn} / \mathrm{cm}^{2}$ in LVH, respectively, NS) followed by $120 \mathrm{~min}$ of $\left[{ }^{3} \mathrm{H}\right]$ phenylalanine perfusion, the control hearts exhibited a $65 \%$ increase of phenylalanine incorporation $(P$ $<0.05$ vs baseline), whereas a similar high level of systolic wall stress resulted in a markedly blunted response in $\mathrm{LVH}$ hearts (35\% increase, $P=$ NS vs baseline) (Fig. 1 ).

Effects of angiotensin II and norepinephrine on amino acid incorporation. $60 \mathrm{~min}$ of angiotensin II/prazosin infusion followed by $120 \mathrm{~min}$ of vehicle perfusion resulted in a $390 \%$ increase of phenylalanine incorporation in left ventricles of control hearts $(P<0.005$ vs baseline $)$. In contrast, the increase in phenylalanine incorporation in left ventricles of LVH hearts was limited to a $53 \%$ increase ( $P=$ NS vs baseline), that was significantly less than in age-matched controls $(P<0.005$ vs controls) (Fig. 2, right panel). Similarly, norepinephrine infusion resulted in a significant increase of phenylalanine incorporation in control hearts, albeit smaller than that seen with angiotensin II (Fig. 2, left panel). As compared with control hearts, the induction of protein synthesis in response to norepinephrine infusion was significantly blunted in the LVH hearts (Fig. 2, left panel).

Effects of wall stress and norepinephrine on protooncogene expression. Since protooncogenes may be important participants in signalling pathways leading to induction of protein synthesis, we studied the effects of the abrupt elevation of wall stress and 


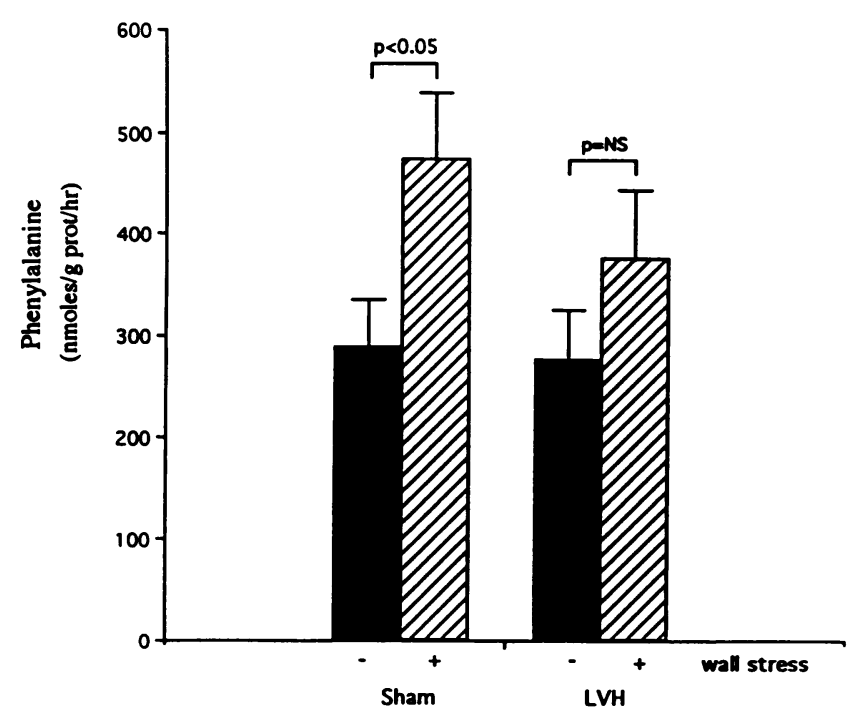

Figure 1. Effects of elevated wall stress on amino acid incorporation in normal and hypertrophied rat hearts. LVH hearts had been subjected to $12 \mathrm{wk}$ of aortic banding whereas control hearts had been subjected to sham operation. Each bar represents the mean \pm SE for six hearts per group; statistics were carried out by ANOVA for multiple comparisons. The symbols - and + represent the absence or presence of the imposition of identical levels of systolic wall stress. Under baseline perfusion conditions, the incorporation of $\left[{ }^{3} \mathrm{H}\right]$ phenylalanine into cardiac proteins was similar in age-matched control and LVH hearts. However, the increase of new protein synthesis after stimulation with the acute imposition of elevated systolic wall stress was markedly blunted in hypertrophied hearts.

norepinephrine on the induction of the c-fos, c-jun, c-myc and EGR-1 mRNA levels. When hearts were studied at the time point of maximal induction, i.e., $60 \mathrm{~min}$ for c-fos and c-jun, and 120 min for EGR-1 and c-myc (data not shown), hypertrophied hearts were characterized by a significantly blunted induction of these protooncogenes relative to the normal control hearts (Fig. 3, left, and Table II). We confirm our previous observation that norepinephrine infusion results in a marked induction of these protooncogenes in normal adult isolated hearts (31). However, the present study shows that this response was significantly blunted or completely absent in hearts with established LVH (Right panel Fig. 3, right, and Table II). We confirm our previous observation that upon wall stress imposition, LVH hearts display a blunted response of c-fos and c-jun mRNA induction (10). In addition, LVH hearts failed to augment EGR1 and c-myc levels after imposition of left ventricular wall stress (Table II).

To avoid the potential for negative feedback of c-fos protein on c-fos mRNA levels (23), additional hearts were perfused with the inhibitor of protein synthesis cycloheximide in parallel to the abrupt imposition of wall stress or infusion of norepinephrine. The superinduction of protooncogene mRNA in response to relief of feedback inhibition by cycloheximide resulted in significantly higher c-fos levels in normal control as compared to LVH hearts (Fig. 4).

\section{Discussion}

LVH is an adaptive cardiac response to the imposition of longterm pressure overload of the heart $(6,32)$. However, clinical observations suggest that the heart's capacity to hypertrophy is limited (33-35). The initial benefits of cardiac hypertrophy such as normalization of wall stress and preservation of systolic force generation may be offset during the late stages of chronic hemodynamic overload (6). Progressive cell loss, myocardial fibrosis, and deterioration of cardiac function may ensue $(7,12$, $13,36)$, suggesting exhaustion or failure to initiate and sustain adaptive cell growth mechanisms. Despite careful investigations that have identified a variety of factors that initiate hypertrophy, little is known about the molecular response to hypertrophic stimuli in hearts with established hypertrophy undergoing the
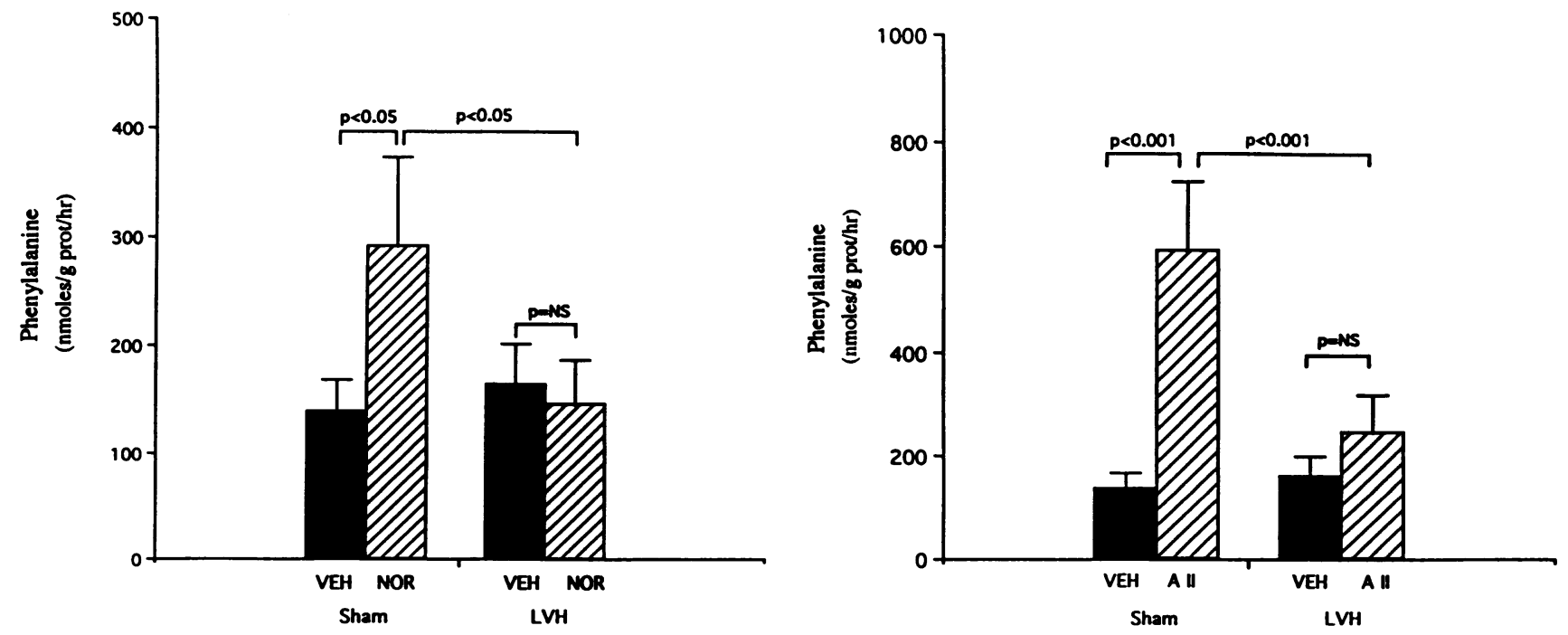

Figure 2. Effects of norepinephrine (left panel) and angiotensin II (right panel) infusion on amino acid incorporation in normal and hypertrophied rat hearts. Each bar represents the mean \pm SE for six hearts per group. As compared with vehicle perfusion, age-matched control hearts perfused with norepinephrine $(N O R)$ or angiotensin II $(A I I)$ in combination with the $\alpha_{1}$-blocker prazosin displayed a significant stimulation of net protein synthesis as measured by incorporation of $\left[{ }^{3} \mathrm{H}\right]$ phenylalanine into cardiac proteins during a 3-h perfusion protocol. In contrast, hearts with LVH displayed no or minimal increase of new protein synthesis with either norepinephrine or angiotensin II. 
Table II. Left Ventricular Protooncogene mRNA Levels of Age-matched Control and LVH Hearts at Baseline and after Stimulation with Elevated Systolic Wall Stress or Norepinephrine

\begin{tabular}{|c|c|c|c|c|c|c|c|c|}
\hline & \multicolumn{4}{|c|}{ Systolic wall stress } & \multicolumn{4}{|c|}{ Norepinephrine } \\
\hline & \multicolumn{2}{|c|}{ Control } & \multicolumn{2}{|c|}{ LVH } & \multicolumn{2}{|c|}{ Control } & \multicolumn{2}{|c|}{ LVH } \\
\hline & - & + & - & + & - & + & - & + \\
\hline $\mathrm{n}$ & 5 & 5 & 5 & 5 & 5 & 5 & 5 & 5 \\
\hline c-fos (c-fos/GAPDH ratio) & $.19 \pm .03$ & $.70 \pm .10^{\ddagger}$ & $.30 \pm .05$ & $.37 \pm .05^{8}$ & $.24 \pm .04$ & $.64 \pm .06^{\ddagger}$ & $.18 \pm .03$ & $.31 \pm .06^{8}$ \\
\hline c-jun (c-jun/GAPDH ratio) & $.21 \pm .03$ & $.63 \pm .09^{\ddagger}$ & $.18 \pm .03$ & $.35 \pm .06^{8}$ & $.29 \pm .02$ & $.45 \pm .05 *$ & $.21 \pm .03$ & $.24 \pm .06^{8}$ \\
\hline c-myc (c-myc/GAPDH ratio) & $.52 \pm .10$ & $1.95 \pm .30^{\ddagger}$ & $.76 \pm .20$ & $1.05 \pm .30^{8}$ & $.96 \pm .1$ & $1.79 \pm .2^{\ddagger}$ & $.80 \pm .1$ & $.84 \pm .20^{5}$ \\
\hline EGR-1 (EGR-1/GAPDH ratio) & $.83 \pm .10$ & $1.59 \pm .20^{\ddagger}$ & $.66 \pm .20$ & $.83 \pm .40^{\S}$ & $.71 \pm .09$ & $1.92 \pm .2^{\ddagger}$ & $.96 \pm .1$ & $1.28 \pm .30^{8}$ \\
\hline
\end{tabular}

All values are expressed as normalized relation to GAPDH mRNA levels and expressed in mean \pm SEM. Stimulation with elevated systolic wall stress or norepinephrine infusion was carried out for $60 \mathrm{~min}$, respectively; - and + represent without and with stimulation. After $60 \mathrm{~min}$ of perfusion, c-fos and c-jun mRNAs were quantified. Hearts for measurements of c-myc and EGR-1 were perfused for another 60 min, without stimulation before quantification of these mRNAs was carried out. ${ }^{*} P<0.05$ vs baseline; ${ }^{\ddagger} P<0.01$ vs baseline; ${ }^{8} P<0.01$ vs age-matched controls.

transition of physiological hypertrophy to cardiomyopathy of overload (5).

The present study was performed to examine immediate cardiac growth responses in hearts with established LVH due to chronic pressure overload. The experimental model of ascending aortic banding in weanling rats was employed for induction of LVH $(17,18)$. Left ventricular weight was only mildly elevated after $8 \mathrm{wk}$ of aortic banding. At $12 \mathrm{wk}$ of aortic banding, the maximal left ventricular to body weight ratio was reached. Thereafter, the increase in left ventricular weight was less pronounced and slower than that of body weight, suggesting that the rate of adaptive cardiac growth may slow down during progression of the disease. Further, recent studies from our laboratory have rigorously characterized left ventricular func-

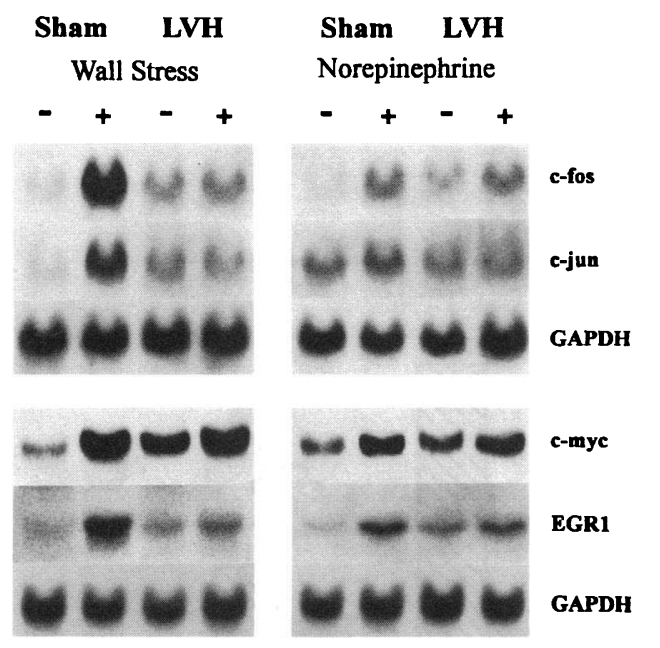

Figure 3.Effects of elevated wall stress and norepinephrine on protooncogene expression in normal and hypertrophied rat hearts. The figure shows representative Northern blot analyses of early immediate gene mRNA levels of age-matched control and LVH hearts stimulated with the abrupt elevation of systolic wall stress (left) or norepinephrine infusion (right). Both systolic wall stress and norepinephrine resulted in significant stimulation of c-fos, c-jun, and c-myc and EGR-1 mRNA levels in age-matched control hearts, whereas a significantly blunted response was observed in LVH hearts. tion and alterations of steady state gene expression in this model $(17,18,20)$. In particular, we have shown that left ventricular systolic function is well preserved at $12 \mathrm{wk}$ after banding. In contrast, transition to failure with cardiac dilatation and premature death is apparent $20-22$ wk after banding (18-20). Thus, cardiac function in this model of left ventricular pressure overload hypertrophy takes a similar course over a compressed time span as that described in human disease (6).

In the present study, the effect of established left ventricular hypertrophy on factors critical for stimulation of cardiac growth was thus studied before cardiac decompensation and interstitial fibrosis were evident. The acute elevation of left ventricular systolic wall stress to similar levels in LVH and control hearts, as well as norepinephrine and angiotensin II infusions were used to stimulate the early growth responses such as induction of protein synthesis and stimulation of early immediate genes which have been well characterized in normal hearts and isolated myocytes without chronic hypertrophy. In our study, a defined level of elevated systolic wall stress failed to induce protein synthesis in rat hearts with chronic hypertrophy that had been exposed to $12 \mathrm{wk}$ of pressure overload. In contrast, sham operated control hearts responded to similar levels of meridional systolic wall stress with a significant stimulation of amino acid

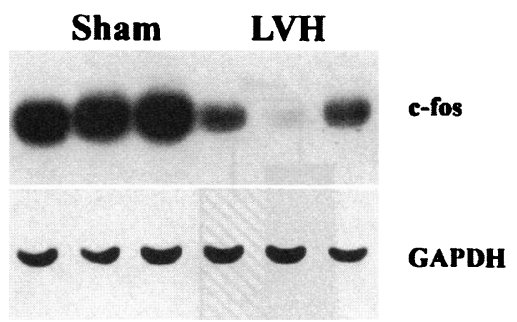

Figure 4. Effects of cycloheximide on c-fos mRNA after stimulation with elevated wall stress in normal and hypertrophied rat hearts. The figure shows representative Northern blot analyses of c-fos mRNA levels of age-matched control and LVH hearts stimulated with elevated isovolumic wall stress after administration of cycloheximide. Cycloheximide was infused in parallel with the elevation of systolic load to inhibit new protein synthesis, including c-fos protein, and thereby relieve feedback inhibition of c-fos protein on c-fos mRNA transcription. Expression of c-fos mRNA levels was markedly higher in age-matched control hearts as compared to LVH, suggesting that negative feedback mechanisms do not account for differences in c-fos expression between control and LVH hearts. 
incorporation into cardiac proteins, corroborating our prior observations in normal adult perfused rat hearts (31). The data in the present study extend recent findings of in vivo measurements of cardiac protein synthesis that demonstrated maximal induction of protein synthesis within $24 \mathrm{~h}$ of cardiac pressure overload but impaired rates of protein synthesis and degradation during long-term compensatory hypertrophy (36-39). In conjunction with the data presented here, it may be concluded that chronic left ventricular hypertrophy is characterized by a depressed capacity for new cardiac protein synthesis that occurs even when the imposed stimulus, e.g., meridional wall stress, is similar in control and LVH hearts.

Neurohormonal activation may substantially contribute to adaptive growth of the heart (5). In particular, both norepinephrine and angiotensin II have been suggested to participate in the initiation of cardiac hypertrophy $(1,40-43)$. In agreement with this hypothesis, the present study corroborates our previous finding that normal isolated control hearts respond to norepinephrine and angiotensin II with marked stimulation of cardiac protein synthesis even when the ventricle is completely unloaded (31). In contrast, hearts with established LVH displayed no effect of norepinephrine and angiotensin II on new protein synthesis, suggesting a markedly blunted growth response to these neurohormonal stimuli.

We also studied the effects of growth stimuli on the induction of early immediate genes. We have previously shown that acute imposition of systolic load induces expression of c-fos and c-jun protooncogenes in normal isolated perfused hearts, whereas the response in hypertrophied hearts appeared blunted (10). The present study extends these findings. In particular, in contrast to age-matched controls, hearts with established LVH inhibit markedly blunted increases in c-myc and EGR-1 mRNA levels when stimulated with elevated wall stress. Likewise, we now demonstrate that stimulation with norepinephrine results in a muted increase of c-fos, c-jun, EGR-1 and c-myc levels in hearts with established LVH. The data reinforce the concept that the molecular response to major growth stimuli is profoundly down-regulated in hearts with chronic left ventricular hypertrophy.

A limitation of the present study is that the mechanism of impaired effects of acute imposition of systolic wall stress and norepinephrine on early immediate gene induction in LVH cannot be elucidated. In particular, the question of whether an intrinsic alteration of myocardial responsivity or receptor downregulation may explain our findings in hearts with LVH remains open. Differences in hemodynamic responses to neurohormonal stimuli cannot explain findings in the present study since neurohormonal stimulation was carried out in isolated hearts in which the flaccid left ventricle did not develop pressure, and coronary vascular pressurization was comparable between groups. Negative feedback inhibition (28) of mRNA expression in LVH does not appear to contribute to the differences between the groups, since differences in c-fos mRNA levels between LVH and control hearts were still evident when cycloheximide was administered to block synthesis of c-fos protein before stimulation. Similarly, differences in the intracellular response to changes in systolic signalling may not explain the different levels of protooncogene expression, since we have previously shown (10) that calcium ionophore administration results in similar levels of c-fos and c-fun protooncogenes in normal and hypertrophied rat hearts.

With respect to data on down-regulation of the alpha-adren- ergic and $\mathrm{AT}_{1}$-angiotensin II receptors in $\mathrm{LVH}(44)$, it is attractive to speculate that the impaired response to growth stimuli may be in part related to alterations at the level of membrane receptors or receptor coupling. In addition, downstream responses to neurohormone receptor activation appear to differ in hypertrophied versus normal myocytes. For example, we have recently shown a significant difference in angiotensin and endothelin-induced changes in intracellular $\mathrm{pH}$ and calcium in isolated control and hypertrophied myocytes from this model (45). Thus, the failure of the intact hypertrophied heart to mount a robust early growth response to these stimuli may reside in changes in intracellular receptor signaling pathways as well as membrane receptor availability. The mechanoreceptor that allows sensing of elevated systolic cardiac load has not been identified yet. Thus further studies are needed to identify the molecular mechanisms of the blunted acute response to growth stimuli responses in hearts with established LVH.

In summary, these observations indicate that major growth stimuli such as the acute elevation of systolic wall stress, norepinephrine, and angiotensin II are far less effective in triggering the immediate cardiac response in hypertrophied as compared with normal adult rat hearts. Impaired induction of protein synthesis in rat hearts with established LVH was preceded by a failure to induce protooncogenes such as c-fos, c-jun, c-myc, and EGR-1. The data suggest a marked down-regulation of early signaling pathways involved in cellular adaptation in response to mechanical and neurohormonal stimulation in hearts with chronic hypertrophy. In this model, the molecular down-regulation of the response to these growth stimuli occurs before the development of mechanical decompensation in the hypertrophied hearts, suggesting that it may contribute to the transition from compensatory hypertrophy to failure.

\section{Acknowledgments}

We thank Dr. Seigo Izumo for critical discussion and support of this work and Dr. Inder M. Verma and Dr. Daniel Nathans for providing the cDNA probes. We also thank Markus Schneider and Georg Huber for technical support of these studies, and Jessica Kespohl for assistance in manuscript preparation.

This work was supported in part by grants from National Heart, Lung, and Blood Institute Grants HL-38189 (B. H. Lorell and E. O. Weinberg), HL-44431, and HL-52864 (B. H. Lorell), the Deutsche Forschungsgemeinschaft (H. Schunkert), and an Astra Award for Cardiovascular Research (H. Schunkert).

\section{References}

1. Sadoshima, J., Y. Xu, H. S. Slayter, and S. Izumo. 1993. Autocrine release of angiotensin II mediates stretch-induced hypertrophy of cardiac myocytes in vitro. Cell. 1993:75:977-984.

2. Izumo, S., B. Nadal-Ginard, and V. Mahdavi. 1988. Protooncogene induction and reprogramming of cardiac gene expression produced by pressure overload. Proc. Natl. Acad. Sci. USA. 85:339-343.

3. Harsdorf, R. V., R. E. Lang, M. Fullerton, and E. A. Woodcock. 1989. Myocardial stretch stimulates phosphatidyl inositol turnover. Circ. Res. 65:494501.

4. Kent, R. L., J. K. Hoober, and G. Cooper IV. 1989. Load responsiveness of protein synthesis in adult mammalian myocardium: role of cardiac deformation linked to sodium influx. Circ. Res. 64:74-85.

5. Morgan, H. E., and K. Baker. 1991. Cardiac hypertrophy: mechanical, neural, and endocrine dependence. Circulation. 83:13-26.

6. Katz, A. M. 1990. Cardiomyopathy of overload. A major determinant of prognosis in congestive heart failure. N. Engl. J. Med. 322:100.

7. Capasso, J. M., T. Palackal, G. Olivetti, and P. Anversa. 1990. Left ventricular failure induced by long-term hypertension in rats. Circ. Res. 66:1400-1417. 
8. Isoyama S., W. Grossman, and J. Y. Wei. 1988. Effect of age on myocardial adaptation to volume overload in the rat. J. Clin. Invest. 81:1850-1857.

9. Takahashi, T., H. Schunkert, S. Isoyama, J. Y. Wei, R. Nadal-Ginard, W. Grossman, and S. Izumo. 1992. Age-related differences in the expression of protooncogenes and contractile protein genes in response to pressure overload in the rat myocardium. J. Clin. Invest. 89:939-946.

10. Schunkert, H., L. Jahn, S. Izumo, C. Apstein, and B. H. Lorell. 1991 Localization and regulation of $c$-fos and $c$-jun protooncogene induction by systolic wall stress in normal and hypertrophied rat hearts. Proc. Natl. Acad. Sci. USA. 88:11480-11484.

11. Ferrario, C. M., M. M. Spech, R. C. Tarazi, and Y. Doi. 1979. Cardiac pumping ability in rats with experimental renal and genetic hypertension. Am. $J$. Cardiol. 44:979-985.

12. Weber, K. T., and C. G. Brilla. 1990. Pathological hypertrophy and cardiac interstitium. Circulation. 83:1849-1865.

13. Olivetti, G., R. Ricei, C. Lagrasta, E. Maniga, E. H. Sonnenblick, and P. Anversa. 1988. Cellular basis of wall-remodeling in long-term pressure overloadinduced right ventricular hypertrophy in rats. Circ. Res. 63:648-657.

14. Schunkert, H. V. J. Dzau, S. S. Tang A. T. Hirsch, C. Apstein, and B. H. Lorell. 1990. Increased rat cardiac angiotensin converting enzyme activity and mRNA levels in pressure overload left ventricular hypertrophy: effects on coronary resistance, contractility and relaxation. J. Clin. Invest. 86:1913-1920.

15. Schunkert, H., B. Jackson, S. S. Tang, F. Schoen, J. F. M. Smits, C. S. Apstein, and B. H. Lorell. 1993. Distribution and functional significance of cardiac angiotensin converting enzyme in hypertrophied rat hearts. Circulation. 87:13281339.

16. Williams, I. A., B. H. L. Chua, R. H. Sahms, D. Siehl, and H. E. Morgan 1980. Effect of diabetes on protein turnover in cardiac muscle. Am. J. Physiol. 239:E178-185.

17. Feldman, A. M., E. O. Weinberg, P. E. Ray, and B. H. Lorell. 1993 Selective changes in cardiac gene expression during compensated hypertrophy and the transition to cardiac decompensation in rats with chronic aortic banding Circ. Res. 73:184-192.

18. Weinberg, E. O., F. J. Schoen, D. George, Y. Kagaya, P. S. Douglas, S. E. Litwin, H. Schunkert, C. R. Benedict, and B. H. Lorell. 1994. Angiotensinconverting enzyme inhibition prolongs survival and modifies the transition to heart failure in rats with pressure overload hypertrophy due to ascending aortic stenosis. Circulation. 90:1410-1422.

19. Bruckschlegel, G., S. R. Holmer, K. Jandeleit, D. Grimm, F. Muders, E. P. Kromer, G. A. J. Riegger, and H. Schunkert. 1995. Blockade of the reninangiotensin system in cardiac pressure-overload hypertrophy in rats. Hypertension. 25:250-259.

20. Litwin, S. E., S. E. Katz, E. O. Weinberg, B. H. Lorell, G. P. Aurigemma, and P. S. Douglas. 1995. Serial echocardiographic-Doppler assessment of left ventricular geometry and function in rats with pressure-overload hypertrophy: chronic angiotensin-converting enzyme inhibition attenuates the transition to heart failure. Circulation. 91:2642-2654.

21. Morgan, H. E. D. C. N. Earl, A. Broadus, E. B. Wolpert, K. E. Giger, and L. S. Jefferson. 1971. Regulation of protein synthesis in heart muscle. I. Effect of amino acid levels on protein synthesis. J. Biol. Chem. 246:2152-2162.

22. Richardt, G., R. Kranzhofer, M. Haass, and A. Schömig. 1990. Angiotensin converting enzyme inhibitors and cardiac noradrenaline release. Circulation. 82 (Suppl III):III-455.

23. Sunga, P. S., and S. W. Rabkin. 1992. Angiotensin II-induced protein phosphorylation in the hypertrophied heart of the Dahl rat. Hypertension. 20:633642.

24. Butterfield, M. C., and R. Chess-Williams. 1990. Enhanced $\alpha$-adrenoceptor responsiveness and receptor number during global ischaemia in the Langendorff perfused rat heart. Br. J. Pharmacol. 100:641-645.

25. Scholz, J., U. Troll, P. Sandig, W. Schmitz, H. Scholz, and J. Schulte am
Esch. 1992. Existence and alpha 1-adrenergic stimulation of inositol polyphosphates in mammalian heart. Mol. Pharm. 42:134-140.

26. Higuchi, M., S. Ikema, and M. Sakanashi. 1992. Correlation of contractile dysfunction and abnormal tissue energy metabolism during hypoperfusion with norepinephrine in isolated rat hearts: differences between normal and diabetic hearts. J. Mol. Cell. Cardiol. 24:1125-1141.

27. Martinussen, H. J., A. Waldenstrom, and G. Ronquist. 1994. Dynamic changes of myocardial inositoltriphosphate and cyclic nucleotides: relationship to contractile response in the perfused working rat heart after adrenergic and muscarinic agonist stimulation. Acta Physiol. Scand. 150:133-139.

28. Müller, R., R. Bravo, J. Burckhardt, and T. Curran. 1984. Induction of cfos gene/I and protein by growth factors precedes activation of c-myc. Nature (Lond.). 312:716-720.

29. Chirgwin, J. M., A. H. Pryzbyla, R. J. MacDonald, and W. J. Rutter. 1979. Isolation of biologically active ribonucleic acid from sources enriched in nuclease. Biochemistry. 18:5294-5299.

30. Sambrook, J., E. I. Fritsch, and T. Maniatis. 1989. Molecular cloning. A laboratory manual. 2nd ed. Cold Spring Harbor Laboratory Press.

31. Schunkert, H. S., J. Sadoshima, T. Cornelius, Y. Kagaya, E. O. Weinberg, S. Izumo, G. Riegger, and B. H. Lorell. 1995. Angiotensin II-induced growth responses in isolated adult rat hearts: evidence for load-independent induction of cardiac protein synthesis by angiotensin II. Circ. Res. 76:489-497.

32. Levy, D. 1991. Clinical significance of left ventricular hypertrophy: insights from the Framingham Study. J. Cardiovasc. Pharmacol. 16(Suppl 2):S1S6.

33. Grossman, W., D. Jones, and I. P. McLaurin. 1975. Wall stress and patterns of hypertrophy in the human left ventricle. J. Clin. Invest. 56:56-64.

34. Grossman, W. 1980. Cardiac hypertrophy: useful adaptation or pathologic process. Am. J. Med. 69:576-584.

35. Pellica, A., B. J. Maron, A. Spataro, M. A. Proschan, and P. Spirito. 1991. The upper limit of physiologic cardiac hypertrophy in highly trained elite athletes.

N. Engl. J. Med. 324:295-301.

36. Katz, A. M. 1990. Angiotensin II: Hemodynamic regulator or growth factor? J. Mol. Cell. Cardiol. 22:739-747.

37. Meerson F. Z., M. P. Javich, and M. I. Lerman. 1978. Decrease in the rate of RNA and protein synthesis and degradation in the myocardium under long-term compensatory hyperfunction and on aging. J. Mol. Cell. Cardiol. 10:145-159.

38. Everett, A. W., M. P. Sparrow, and R. R. Taylor. 1979. Early changes in myocardial protein synthesis in vivo in response to right ventricular pressure overload in the dog. J. Mol. Cell. Cardiol. 11:1253-1263.

39. Ray, A., M. C. Aumont, J. Aussedat, J. Bercovici, A. Rossi, and B. Swynghedauw. 1987. Protein and 28S ribosomal RNA fractional turnover rates in the rat heart after abdominal aortic stenosis. Cardiovasc. Res. 21:587-592.

40. Khairallah, P. A., and J. Kanabus. 1983. Angiotensin and myocardial protein synthesis. Perspect. Cardiovasc. Res. 8:337-347.

41. Khairallah, P. A., A. I. Robertson, and D. Davila. 1972. Effects of angiotensin on DNA, RNA, and protein synthesis. In Hypertension '72. J. Genest and E. Koiw, editors. New York, Springer-Verlag, 212-220.

42. Baker, K. M., and J. F. Aceto. 1990. Angiotensin II stimulation of protein synthesis and cell growth in chick heart cells. Am. J. Physiol. 259:H610-618.

43. Simpson, P. C., K. Kariya, L. R. Karns, C. S. Long, and J. S. Karliner 1991. Adrenergic hormones and control of cardiac myocyte growth. Mol. Cell. Biochem. 104:35-43.

44. Lopez, J. J., B. H. Lorell, J. R. Ingelfinger, E. O. Weinberg, H. Schunkert, D. Diamant, and S-S. Tang. 1994. Distribution and function of cardiac AT ${ }_{1}$ - and $\mathrm{AT}_{2}$-receptor subtypes in hypertrophied rat hearts. Am. J. Physiol. 267:H844H852.

45. Ito N, Y. Kagaya Y, E. O. Weinberg, and B. H. Lorell. 1994. Effects of endothelin on cell shortening and intracellular $\mathrm{Ca}^{2+}$ in hypertrophied myocytes. (Abstract). Circulation. 90:1-537. 